MIDPI

sciforum
MOL2NET, International Conference Series on Multidisciplinary Sciences

06. MODECO-05: Molec. Diversity \& Ecosystems, Puyo, Ecuador-Porto, Portugal-Paris,

France, EPA, USA, 2020

\title{
Characterization of the working conditions in paneleras of the Pastaza canton, Ecuador
}

\author{
Santiago Aguiar ${ }^{1}$,Edgar Chicaiza ${ }^{2}$,Hernán Uvidia ${ }^{1}$, Willan Caicedo ${ }^{1,3}$ \\ ${ }^{1}$ Facultad de Ciencias de la Tierra, Universidad Estatal Amazónica, Puyo, Pastaza, Ecuador \\ ${ }^{2}$ Facultad de Ciencias de la Vida, Universidad Estatal Amazónica, Puyo, Pastaza, Ecuador \\ ${ }^{3}$ Granja Agropecuaria Caicedo, Puyo, Pastaza, Ecuador
}

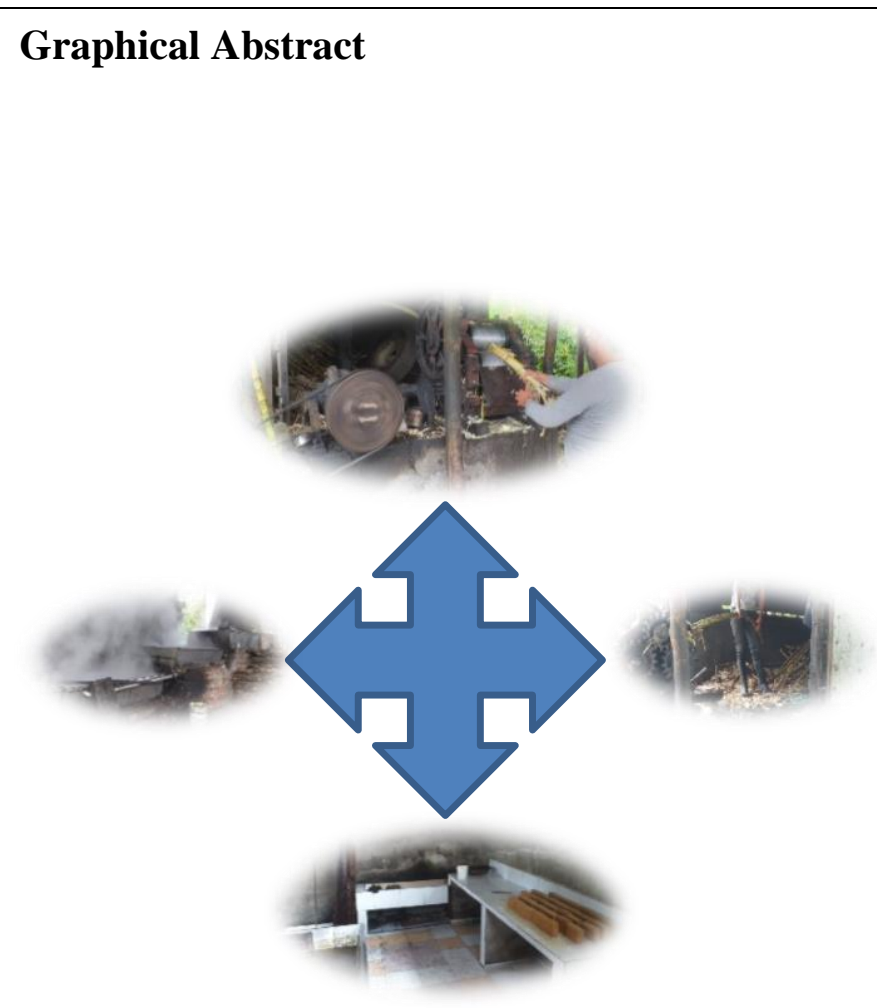

Abstract

The objective of this research was to carry out a diagnosis of the working conditions in the panela industry in the Pastaza canton, Ecuador to propose a solution on the priority dangers of occupational accident. The population was made up of 208 workers from 7 panela producers in the Pastaza canton of the Tarqui and Puyo parishes, different field visits were carried out for data collection and instruments were applied such as: checklist, identification guide of Hazards and risk assessment in occupational health and safety Colombian Technical Guide "GTC" 45. In the analysis of the results, it was evidenced that the workers in this sector have a low level of education, most of them are men, with many years in activity routine and with a lack of knowledge of Occupational Safety and Occupational Health regulations and legislation, with long working hours. $40 \%$ of workers carry out heavy lifting, $100 \%$ repetitive movements, $80 \%$ of workers are exposed to psychosocial risk factors, $60 \%$ of establishments have adequate lighting, and $100 \%$ present greater risks (fire). The working conditions in the paneleras of the Pastaza canton, Ecuador, do not comply with the legislation on Occupational Safety and Health, and highly and 
gradually affect productivity in the microenterprise sector.

Key words: Ecuadorian Amazon, working conditions, ergonomics, disturbances, paneleras, productivity.

\section{Introduction}

Human resources and the relationship with working conditions are directly related to efficiency and productivity, ensuring that agribusinesses strive to create a healthy environment in balance with the capabilities of workers and working conditions (Escobar, 2017).

In Ecuador, the panela production chain is made up of public and private actors, by productive and commercial links. In the province of Pastaza, the production of panela represents a very important item in the economy, which generates and provides work to families through participation in the cultivation, processing, transportation and marketing processes (Sablón et al., 2016).

Currently, in Ecuador there is no information on accidents and occupational diseases derived from activities carried out during industrialization, the latest statistics that can be referred to are those of 2013. According to Baldeón (2013), in Ecuador, in 2013 the General Occupational Risk Insurance records 16,458 accidents, classified into 13,566 accidents arising during working hours, typical accidents, commission and service mission, outside the workplace itself on the occasion or as a consequence of the activities entrusted, and 2,892 accidents recorded as "in itínere" considered as on the way home from work or vice versa.

The importance of carrying out the characterization of the working conditions in the paneleras of the Pastaza canton is framed in identifying the risks to which the workers in this sector are exposed. The objective of this research was to carry out a diagnosis of the working conditions in the panela industry in the Pastaza canton, Ecuador to propose a solution on the priority dangers of occupational accidents.

\section{Materials and Methods}

The research was descriptive or diagnostic, since through direct observation with observation sheets and interview questionnaire, the working conditions were identified to determine the existing hazards. The assessment was made qualitatively and quantitatively, using the Colombian Technical Guide 45 of the Colombian Institute of Technical Standards, the identification and assessment of risks, elements, working conditions, phenomena or human actions that involve the potential capacity to cause accidents and damage to the health of workers, facilities, machines and the environment.

A descriptive survey, with open questions, was applied to the workers to determine the characteristics of the sample, such as: age, sex, education, seniority at work, occupational risk factors to which they are exposed, job design work and environmental conditions.

The population was made up of 208 workers from 7 paneleras of the Pastaza canton, Tarqui and Puyo parishes (the Americas sector). In the study, a sample of 82 workers was used in the 7 paneleras.

\section{Results and Discussion}

Figure 1 shows the distribution of workers in the paneleras, according to age and sex. 


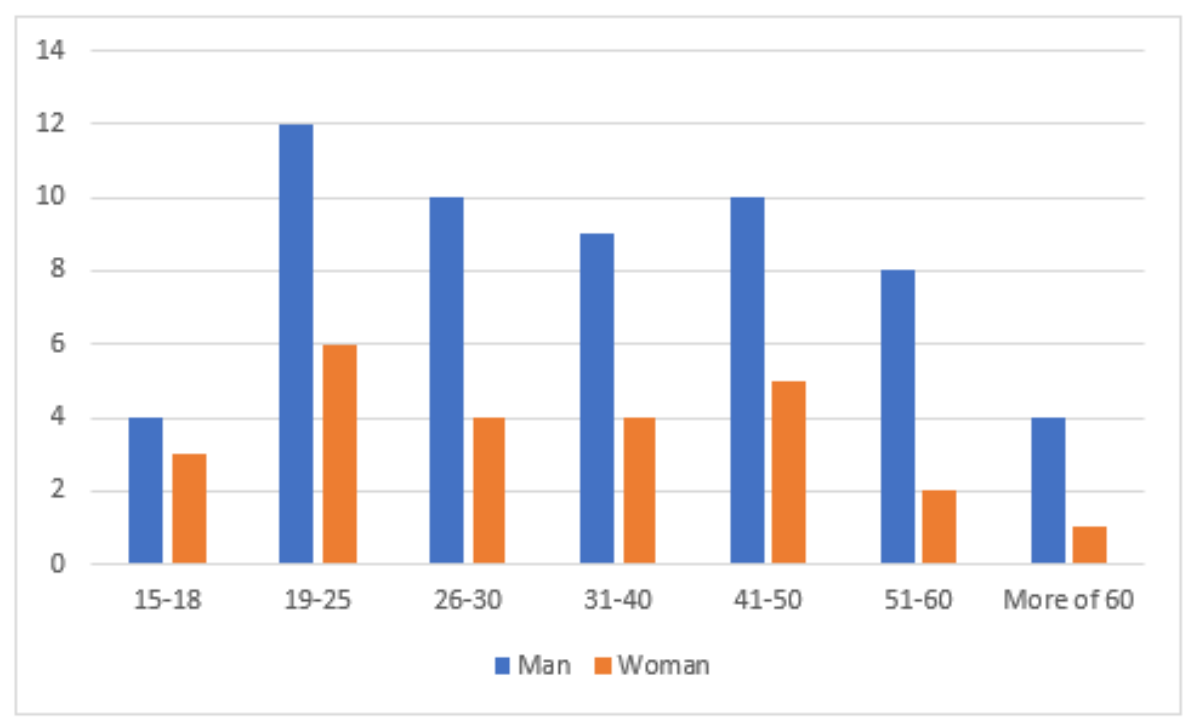

Figure 1. Distribution of workers according to age and sex in the paneleros of the Pastaza cantón

Table 1 shows the level of schooling of workers from the paneleros of the Pastaza canton.

Table 1. Level of Education

Scholarship

Illiterate

Incomplete Basic Education

Complete Basic Education

Incomplete high school

Complete baccalaureate

Total
Number of workers

7

15

17

22

21

82
Percent

8.54

18.29

20.73

26.83

25.61

100.0

Table 2 shows the affiliation of workers to the Ecuadorian Social Security Institute.

Table 2. Affiliation of workers to the Ecuadorian Social Security Institute

\begin{tabular}{lcc}
\hline $\begin{array}{l}\text { Affiliation to the Ecuadorian Social } \\
\text { Security Institute }\end{array}$ & $\begin{array}{c}\text { Number } \\
\text { workers }\end{array}$ & $\begin{array}{c}\text { of } \\
\text { Percent }\end{array}$ \\
\hline Work Risks & 15 & 18.29 \\
Peasant insurance & 40 & 48.78 \\
None & 27 & 32.93 \\
Total & $\mathbf{8 2}$ & $\mathbf{1 0 0 . 0}$ \\
\hline
\end{tabular}


The main risks identified in the paneleras and their possible consequences were:

Physical: Eye fatigue, tiredness, headache, stress and accidents, skin rashes, cramps, dehydration, in addition to aggravating previous ailments such as cardiovascular and respiratory diseases.

Chemicals: Bagazosis

Biologicals: Skin rashes, VBD vector-borne diseases, allergies, stings

Biomechanics: Lesions of the musculoskeletal system, lumbar alterations due to lifting the load of panela, cumulative trauma disorders, musculoskeletal system injuries, fatigue, alterations of the vascular system, lumbar and dorsal alterations.

Mechanical: Stress as psychosocial risk and fracture, burns, injury, trauma, amputation.

\section{Conclusions}

The working conditions in the paneleras of the Pastaza canton, Ecuador, do not comply with the Occupational Health and Safety legislation, and highly and gradually affect productivity in the microenterprise sector.

\section{References}

Baldeón, M. 2013. Análisis Estadístico de Accidentalidad Laboral del Ecuador y Comparación con la Accidentalidad Laboral de Colombia del año 2013. Universidad San Francisco de Quito, Quito, Ecuador, $194 \mathrm{p}$.

Escobar, J. 2017. La Gestión del Talento Humano y la Productividad de la Agroempresa Unión Libre. Universidad Técnica de Ambato, Ambato, Ecuador, 83 p.

Sablón, N., Pérez, M., Acevedo, J., Chacón, E. \& Villalba, V. 2016. La integración en la cadena agroalimentaria de panela en el Puyo-Ecuador. Cultivos Tropicales, 37(4): 128-135 